\title{
Environmental discourse of architecture
}

\author{
INCI BASA* \\ Bilkent University, Faculty of Art, Design and Architecture, Department of Interior Architecture and \\ Environmental Design, Bilkent 06800, Ankara, Turkey
}

(Received 3 March 2009)

\begin{abstract}
This study attempts to examine the environmental discourse of architecture. The attempt to constitute a linguistic framework for the environmental discourse requires a critical understanding of the interrelationship among the following concerns: a) discourse as a 'system of statements' that prescribes the 'theoretical formation' of an object, b) architecture as a field in which several discourses (professional, technological, social, representational, theoretical, etc.) operate around their specific objects, c) environmental discourse as a discursive 'formation' which involves verbal or non-verbal 'statements' referring to the problematic of environment. The analysis of the linguistic figures such as clichés, interpretations and definitions, reveals the discursive power of language as a condition in which environmental discourse forms its discursive objects and produces discursive effects in architecture.
\end{abstract}

Keywords: Environmental discourse; Architecture; Linguistic figures

\section{Introduction}

Architecture is a complex field. This complexity can be ascribed to the variety of the interacting theoretical, educational and practical issues. This general view would be insufficient to illustrate the situation specific to architecture and its so-called complexity. For a more distinct illustration, the discursiveness of this complexity has to be underlined. The field of architecture is regulated by a plenitude of discourses, each of which has its own objects, operations and effects. The statements that together form a discourse [1] circulate, set up discursive relationships [2] and arrange the field according to some specific formulations. Professional, technological, social, representational, environmental discourses: all control the field in terms of limitations and conceptualizations. They introduce their priorities and principles through the distribution of a fragmented series of verbal or non-verbal statements, and repression of some others. The fragmentations due to the possible discrepancies do not exist merely among the different discourses, but also within the same discourse.

Architecture provides an appropriate ground for discourses to form their own objects, as it lacks a specific and unique object around which the whole discipline practises. A multitude of objects such as design, building, practice, theory, style, space, form and function, mostly in an uncertain state, supports the establishment and power of discourses. Environmental

*Corresponding author. Email: basa@bilkent.edu.tr 
discourse in the field of architecture, then, has to be identified in this conceptual perspective before any specific observation. At that point, another important emphasis has to be given to the very concept of discourse, because it is an ambiguous term that has to be unfolded. Furthermore, such an emphasis clarifies also the specification and insistence of using the compound of environmental discourse instead of environmentalism or environmental paradigm or trend or movement. Here, it is relevant to underline that not the environmental problematic in architecture and its relationships, but the said, written, thought patterns, which constitute a 'discursive' and 'fragmented unity' are within this problematic.

Discourse is a 'system of statements' [1] which prescribes and describes the theoretical formation of an object through verbal or non-verbal representations. Environmental discourse is a discursive formation that produces some changes in the field of architecture. The aim of this paper is to focus this formation through its linguistic mechanisms. This attempt does not reduce the complexity of discourse. It does not provide a comprehensive view on all aspects of environmental discourse, but it tries to open up a discussion. These limits, however, indicate a broad, complicated and ever-shifting surface rather than a linguistic representation. The framework that this study aims to draw is more or less the framework of the structure of environmental discourse, since language is the essential medium of any discourse through which the discursive power can be observed.

\section{Discourse}

The term discourse does not have a unique definition. The same term is being used with different theoretical points of views. Such disciplines as linguistics, sociology, social psychology, and philosophy adopt their own conceptualizations and formulations [3], applying different discourse analyses. For example, both the examination of 'the use of connectives like, and, or, but, so' [4] and 'the social and material existence of knowledges' [5] fall under the same phrase of discourse analysis. This causes terminological and conceptual confusions. It is necessary to clarify the approach while using the term discourse. There are, in fact, two dominant (and conflicting) perspectives within all these confusions: first, the linguistic perspective which refers to discourse as a purely linguistic matter; second, the theoretical perspective which recognizes discourse as a complex group of relations, irreducible to a mere linguistic concern. The present approach within this general framework can be positioned closer to the second group, though not dismissing the first one.

The discursive relations form a network around a specific object and produce some changes in the field that they practise. The network is regulated by statements that place or replace, strengthen or weaken the objects of that field in order to establish a discursive one. The analysis of this process merely through its linguistic aspects provides an incomplete identification. Nevertheless, it reveals the internal 'mechanism' [2] of a discourse, which constructs and manages the discursive system. In other terms, the linguistic aspect should by no means be conceptualized as a transparent medium through which discourses convey their messages, but rather, itself as a 'mechanism' which controls the so-called 'discursive practice' and its power. In the same manner, a linguistic analysis stripped of its discursive relations can only conclude a narrow identification. It is in this sense that the present approach positions itself somewhere in between the two extremes to observe and to identify the 'theoretical formation' of the objects of environmental discourse in architecture. 


\section{Architecture as a discursive field}

Similar to discourse, the term architecture is commonly used without any conceptual precision. It sometimes refers to a profession and a discipline, or to an artistic formation, or sometimes directly to some distinguished buildings. In fact, this 'illusion of communication', indicates the factual evidence that this term designates a wide ambiguous field. Yet, the linguistic vagueness is essentially the representation of the real condition of architecture, rather than an outgrowth of lack of attention. It is a field that lacks the accurate knowledge of its own practice and objects [6].

Yet, as the field of architecture is parcelled up through a discursive complexity and variety of contexts, paradigms, ideals, positions, conceptualizations, it appears as a fragmented surface that fails to have efficient contacts to the real life. It becomes a field conducted by the statements [1] and their manipulations. The ever-changing densities and fractures, coherences and contradictions, permanencies and disappearances of some specific objects (such as theory, design, art, technology, environment, etc.) establish the unsettling state of architecture. The analytic observation of the statements and their operations is, in this respect, the identification of the whole field as a multiplicity of interacting discourses. Each discourse attempts to coordinate and regulate the field of architecture according to its priorities (as well as its ignorances).

\section{Environmental discourse in architecture}

The relationship between man and nature in spatial context has always occupied the architectural agenda in history. However, as Teymur states in his book Environmental Discourse, during the 1960s and the 1970s the concept of environment has largely replaced those of God, Nature and Man, which dominated the sciences, arts and philosophy as well as architecture and urban thinking in the past. He claims that the concept of environment became the shorthand for nature, world, cities, buildings, space, forests, air, wildlife, energy and scores of other distinct phenomena from housing to whales [2]. Teymur points out that what made this replacement possible was a specific discourse: environmental discourse.

Environmental discourse, in this general context, is one of the effective discourses in architecture that exists in a multiplicity of verbal and non-verbal statements circulating in the field. It theoretically treats its very object of environment, and discursively re-shapes the surface of the field through architectural practice, architectural theory, architectural design, architectural education, architectural legislations, architectural discussions, texts, books, articles, speech, etc. Not only the institutional or individual affirmations but also the attacks against it compose the incoherent body of environmental discourse.

Yet, how is it possible to identify a discourse if it is a whole of disorganized patterns in various forms of statements under some confirming or refuting conditions rather than a unique entity? Since there is not one specific understanding of environmental discourse, there is not one specific way of its analysis, thus identification and observation [7]. Yet one may attempt to constitute a network according to its own understanding which enables one to identify and observe the formation and practice of environmental discourse. This network can be defined as a linguistic web that is discursively processed [6]. The so-called discursive process formulates the 'environmental' statements in order to make them present in the field of architecture, not only as arbitrarily circulating ones but rather as the ever-practising figures of a powerful formation. 
The following items of clear language, vague language, clichés, concepts, interpretations, definitions and classifications, then, have to be considered as the mechanisms that transform the linguistic conditions into discursive formations. Their grouping, which is borrowed from Chaffee [8], illustrates an even set of representing, socializing and organizing discursive figures. They together regulate the objects of environmental discourse and create the discursive linguistic web.

The objects of environmental discourse are sometimes represented through a clear language that is 'specific, distinct, precise and accurate'. Nevertheless, this linguistic determinacy causes a suspicion if it makes up an 'environmental' indeterminacy, since there may not necessarily be a distinct, precise and accurate thinking behind it [8]. The representations that are furnished to illustrate environment, in fact, have to be questioned if they transparently represent a clear thinking. Composing an absolute image of environment by means of pure expressions and 'overt messages' [9] appears to be a decorative performance rather than a structural act. Actually, an architectural milieu always tends to highlight and accent some aspects such as art, technology, philosophy or environment that would help to formulate a comprehensive mental picture of its own. In this conception, environmental objects that are 'evoked in words' [10] prevail in the discursive field of architecture. A mental picture of environment is constituted from the statements that are first announced by experts with a special knowledge, appreciated by institutions, reproduced by popular enunciators and confirmed by the architectural community. Table 1 displays a collection of statements that illustrate this discursive practice.

Language is an underlying force [22], which establishes the environmental conceptualization of architecture. A fictive illustration of environment is formed through some clear statements. Such an illustration of environment is not regulated by a 'real referent' but by some 'discursive mechanisms' [2]. Clear language, on this basis, provides the 'positive conditions' [1] for the existence of a notion of environment.

Table 1. Clear statements

'Interest in ecological design issues has increased enormously over the past few decades and ecological problems are perceived to be on the increase.' [11]

'... concern for architecture's environmental qualities - its role as a physical mediator between people and nature and its effects on the natural world - dates back at least to the 19th century'. [12]

'... the term architectural psychology reflects a trend which unites a number of workers who were concerned with the design of physical environments and subsequent influence on behaviour'. [13]

'... buildings are such an important constituent of urban energy consumption'. [14]

'Environmental design is not new. The cold environment of 350000 years ago led our European ancestors to build shelters under limestone cliffs.' [15]

'An emerging political agenda is represented by the "green architecture" movement, which proposes the need for an environmental ethics of building.' [16]

'If the settlements are organically related to their environment, it implies that they serve as foci where the environmental character is condensed and explained.' [17]

'Correct classicism, ... seeks to differentiate itself from its environment. It is self-contained and exclusive in nature.' [18]

'There are different ways of conceptualizing "the environment", which is too broad a term to be used successfully ...' [19]

'Once the space requirements for the different activities have been determined, the necessary environmental conditions have to be established.' [20]

'... the higher ideal of unity as a more intimate working out of the expression of one's life in one's environment.' [21] 
In opposition to the clear language, vague language has 'blurring messages'. This imprecise and general language [8] is one of the mechanisms that form the environmental discourse. Since the unity of environmental discourse, like all other discourses, can be identified only through its contradictory modes, the coexistence of clear and vague language is not a conflict [6]. Vagueness takes place when the expressed realm is not accurately prescribed. In the case of environment, vagueness is not a linguistic shortcoming but the neutral representation of the vague state of the concept of environment itself within the architectural field.

When the non-specificity of the environmental concepts and terms come together with linguistically vague words with a strong subjective element - such as adjectives, there occurs a confusing indeterminacy. But, environmental discourse is a widely rich formation in respect of these general terms of qualification, evaluation, judgment, etc. The subjective terms especially [23] such as comfortable, beautiful, charming, create a vagueness as they commonly adjoin an ill-defined term which lacks a distinct meaning. Table 2 a shows the use of some adjectives with the purpose of adding more information to a supposedly 'wellknown' term, environment. Yet, the result seems to be an 'informed' vagueness throughout the field of architecture.

Besides these phrases which are commonly used but exceptionally interrogated in the architectural milieu, there are some others which are composed of the 'absolute' but vague constant of 'environmental ...' as shown in table $2 b$. They occupy the verbal and conceptual agenda of architecture without a critical scrutiny as if their semantic pre-structuring is obvious as their syntactic arrangement [6].

Actually, vague words assist the discourse to form and arrange the discursive objects. Vagueness, then, enables the environmental discourse to shape the field according to the promoted discursive conditions.

The environmental discourse of architecture encourages the employment of clichés, the 'overused phrases which represent supposedly true and known relations' [8]. Accordingly, the objects of environmental discourse are established through the widespread repetition of these stereotyped expressions. The ones shown in table 3 and many others circulate on the field of architecture.

Table 2a. Vague phrases I

aesthetic environment, built environment, climatic environment, future environment, green environment, habitable environment, harmonious environment, ideal environment, imaginary environment, material environment, natural environment, organic environment, physical environment, safe environment, selective environment, social environment, spatial environment, sustainable environment, technological environment, traditional environment, vernacular environment, visual environment, etc.

Table 2b. Vague phrases II

environmental character, environmental conditions, environmental constraints, environmental context, environmental control, environmental design, environmental discourse, environmental enhancement, environmental ethics, environmental factors, environmental force, environmental management, environmental meaning, environmental movement, environmental phenomena, environmental problem, environmental program, environmental protection, environmental psychology, environmental quality, environmental realities, environmental relations, environmental research, environmental system, environmental technology, etc.

Table 3. Clichés

'Building-environment relationship', 'environment-behaviour relationship', 'man-environment relationship', 'theory of environmental design', 'environmental design in architecture', 'solid-void relationship', 'indoor-outdoor relationship', ... 
The clichés are practised without any critical thinking. Although the clichés activate an over-simplification of the problematic of environment, they are very effective discursive operations. This 'discursive effectiveness' [2] can be best explained through the density of their 'circulation and accumulation' [1] rather than depicting a reality or constituting a conceptualization.

Concepts are the 'general ideas' [8] that are formed to identify, to organize and to distinguish something abstract. Concepts, established under the authority of a discourse arrange and pattern the related field. Hence, the conceptualization of the field according to these discursive patterns is another powerful discursive strategy [6]. A vast number of general concepts, which do not necessarily have coherence other than a discursive unity, determine and support the experience of the very discursive concept of environment in the architectural milieu. Table 4 illustrates some of these general concepts.

Here, rather than the specificity of each concept, the 'criteria' [1] that brings them together, or eliminates or transforms them have to be underlined. It can be stated that environmental discourse completes its self-presentation through the operation of these concepts.

Interpretation is constitution of various planes for the applicability of the concept. It may either sharpen the definition of the concept or project a subjective position [6]. Interpretations, with their discursive nature enhance the efficiency of the mastering discourse. The field of architecture encourages the use of interpretations, as its prevailing concepts do exist mostly in an indefinite condition lacking a specific knowledge. In this sense, environment itself is a concept, which is being discursively formulated through the mechanisms of interpretations.

Table 4. Concepts

aesthetics, behaviour, body, building, city, civilization, climate, comfort, composition, culture, design, ecology, ecosystem, energy, form, function, government, green, housing, industry, landscape, location, man, material, nature, neighbourhood, participation, people, plan, practice, scale, site, society, space, structure, style, technology, type, user, well-being, etc.

Table 5. Interpretations

'... the desire for integration is not easily realised and part of the struggle is over definitions of architecture and sustainability. The green elite are wary of co-option, yet unless they play the aesthetic game they will be excluded from the field. The art elite are secure at the core of the field, although unsettled by the realisation that if the game does not turn green then the field will turn brown.' [24]

'Environmental design problems are the mental sparks that express a friction in the intimate relationship between a people and a place.' [25]

'Environmental problems concern not only science and technology but also the ideals, myths, and meaning that have associated with nature.' [26]

'The conscious choices architects make when designing buildings not only have a profound influence on human health and well-being but also on local and global environmental degradation.' [27]

'As architecture can acquire its vitality from the sky, the sun, the earth, air and water, so can it transmit this vitality to life.' [28]

'The need to build consideration of environment impact into the design process will pose enormous problems and challenges, but it will also be a stimulus for innovation and creativity.' [29]

'Architecture is but a part of the built environment. Inside a building parts of the building become the whole environment; outside it forms only part of our surroundings.' [30]

'... people interact with the environment rather than to react it'. [31] 
Definitions clarify the meaning of the concepts through certain statements. Although they are constructed to set up complete identifications and definite properties, they may paradoxically incite an indefinite position, especially when they ignore the interwoven relationships of the 'defined' [6]. Yet, almost all the discourses support their positions and get their forms through some 'sound' and 'stable' definitions; which transform the disordered complexities of discursive fields into illusionary but well-formulated clarifications. Environmental discourse, in this conception, formulates itself with the discursive competence of definitions. All the concepts, essentially environment and its conceptual components are secured by a wealth of properly decorated statements. Table 6 shows a collection of such statements.

Classifications are arrangements and distribution of objects that have supposedly similar characteristics and features. The cluster of objects that are recalled under a common name becomes classified and verbally coded [6]. In discursive fields, such as architecture, the classifications rely on the specificities of prevailing discourses rather than the specificities of the objects. Environmental discourse, in this manner, regulates a 'verbal illusion' that successfully divides a discursive whole into compartments through an act of separation. Not only the buildings, but the architecture itself is classified according to the various topics of environment as shown in table $7 \mathrm{a}$.

The concept of environment is graduated as built and unbuilt environment. The built environment is formulated as indoor and outdoor environment. The comfort in indoor

Table 6. Definitions

'Sustainable housing is ... housing with a minimum of negative environmental impacts in terms of climate change; the quality of air, water and soil; noise; stench; the stock of nonrenewable materials; and biodiversity.' [32]

'Environmental field: the conditioned place one finds oneself in when striving to be theoretically and practically aware of the central role of ''interest'" and related actions in the transformations of places.' [33]

'Environmental design is an art that is founded in the craft of place making.' [34]

'A built environment is an ongoing, dynamically unfolding array of signs, existing spatially and temporally.' [35]

'Environment is outward influence. It is defined as "the sum of the influences which affect an organism from without".' [36]

'... architecture is space, and space, environment'. [37]

Table 7a. Classifications I

green architecture, ecological architecture, environmental architecture, climatic architecture, sustainable architecture, organic architecture, urbanist architecture, regionalist architecture, etc.

Table 7b. Classifications II

\footnotetext{
"... Banham suggested that historic buildings fall into three distinct "modes" of environmental control: the "conservative", the "selective" and the "regenerative". ' [39]

'... distinction between man-made and natural is synthetic and primarily intended for analytical purposes'. [40]

'The structure of the place becomes manifest as environmental totalities which comprise the aspects of character and space. Such places are known as "countries", "regions", “landscapes”, “settlements", and "buildings". ' [17]

'The three elemental environments which have cited (the primeval, the communal, and the urban) appear to be "indigenous" to the human mind.' [36]
} 
environment is classified into 'more manageable components' [38] as thermal, luminous, acoustic, etc. Once the classifications are established, the uncertain nature of the field becomes more structured and systematized. The classifications, thus, employ a discursive control over the perception of the environmental concepts. Interestingly, these organizer classifications may not have a more fundamental role other than constituting a manageable (and not necessarily real) field upon which theories, practice, education, design, criticism, etc. become possible. Table $7 \mathrm{~b}$ has examples of such statements that circulate in the field of architecture.

\section{Concluding remarks}

This study is an attempt to illustrate that almost the entire understanding of the factual world is formed and mediated through the linguistic mechanisms in various formations. These mechanisms produce a discursive coherence upon a certain field according to some priorities and they promote a discursive mass of knowledge through 'statements'. The 'rules' [1] of the 'discursive unity' [2] help to shape the objects of that field. In this context, the paper refers to environmental discourse as a 'discursive system of statements', which acquires its 'status' through the discursive performance of a linguistic web. Here, it has to be recognized that this performance relies on the ambiguous nature of the field of architecture that legitimizes itself by means of 'ideal' essences of various discourses instead of its 'factual' objects.

In this sense, a critical understanding of architecture is not possible without exploring the 'discursive system' which 'rules the existence' [1] of objects of architecture. And a critical understanding of discourse is not possible without disclosing architecture as a field despondently expecting a powerful 'object' to fill up its long-standing theoretical void and greed. No doubt, environmental discourse, which begun to be shaped by the architectural (re)discovery of the 'environment', achieved its comprehensive materiality through linguistic figures with the impulse of architectural intention to be 'environmentalized', as once 'aestheticized', or 'socialized', 'scientificized', or 'philosophized', etc. to reproduce and define itself. In this framework, this study specifically aims to contribute to the identification of the environmental discourse of architecture. And, it attempts to initiate a general awareness on the power of 'discursive formations'.

\section{References}

[1] Foucault, M. 1995. The archaeology of knowledge. (6th Ed). London: Routledge.

[2] Teymur, N. 1982. Environmental discourse. London: Question Press.

[3] Schiffrin, D. 1994. Approaches to discourse. Cambridge: Blackwell.

[4] Schiffrin, D. 1992. Discourse markers. (5th Edn). Cambridge: Cambridge University Press.

[5] Macdonell, D., 1986, Theories of Discourse: An Introduction (Oxford: Blackwell).

[6] Basa, I., 2000, Linguistic discourse in architecture. Unpublished PhD thesis, Middle East Technical University, Ankara.

[7] Hansen, A. and Machin, D., 2008, Visually branding the environment: climate change as a marketing opportunity. Discourse Studies, 10(6), 777-794.

[8] Chaffee, J., 1991, Thinking Critically (Boston, MA: Houghton Mifflin).

[9] Dimbleby, R. and Burton, G., 1992, More than Words (London: Routledge).

[10] Wales, K., 1990, A Dictionary of Stylistics (London: Longman).

[11] Vakili-Ardebili, A. and Boussabaine, A. (2007) Design eco-drivers. Journal of Architecture, 12(3), 315-332.

[12] Upton, D., 1998, Architecture in the United States (Oxford: Oxford University Press).

[13] Cassidy, T., 1997, Environmental Psychology (Northampton, MA: Psychology Press).

[14] Guy, S., 2006, Designing urban knowledge: competing perspectives on energy and buildings. Environment and Planning C: Government and Policy, 24(5), 645-659. 
[15] Fordham, M., 1997, Strategies, in: R. Thomas (Ed.) Environmental Design (London: E \& FN Spon).

[16] Nesbitt, K., 1996, Theorizing Architecture Theory 1965-1995 (New York: Princeton Architectural Press).

[17] Norberg-Schulz, C., 1976, The phenomenon of place, in: K. Nesbitt (Ed.) Theorizing Architecture Theory 1965-1995 (New York: Princeton Architectural Press).

[18] Doremus, T.L., 1994, Classical Systems in Modern Architecture (New York: Van Nostrand Reinhold).

[19] Rapoport, A., 1990, The Meaning of the Built Environment, 2nd edn (Tucson: The University of Arizona Press).

[20] Ehrenkrantz, E.D., 1989, Architectural Systems (New York: McGraw-Hill).

[21] Wright, F.L., 1970, Organic architecture, in: U. Conrad (Ed.) Programmes and Manifestoes on the 20th C Architecture (London: Humphries).

[22] Fiske, J. (Ed.), 1992, Key Concepts in Communication (London: Routledge).

[23] Wales, K., 1990, A Dictionary of Stylistics (London: Longman).

[24] Owen, C. and Dovey, K., 2008, Fields of sustainable architecture. Journal of Architecture, 13(1), 9-21.

[25] Diethelm, J., 1998, Designing in an Environmental Field (Eugene, OR: Aurora Books).

[26] Crowe, N., 1995, Nature and the Idea of a Man-made World (Cambridge, MA: MIT Press).

[27] Cole, R., 1994, Charette presentations, in: Architecture and the Environment: Proceedings of the National Conference Symposium of the Royal Arch. Ins. of Canada.

[28] Crowther, R.L., 1992, Ecologic Architecture (Boston, MA: Butterworth Architecture).

[29] Mackenzie, D., 1991, Design for the Environment (New York: Rizzoli).

[30] Day, C., 1990, Places of the Soul (Northamptonshire: The Aquarian Press).

[31] Canter, D., 1981, Psychology for Architects, 2nd edn (London: Applied Science Publishers).

[32] Priemus, H., 2005, How to make housing sustainable? The Dutch experience. Environment and Planning B: Planning and Design, 32, 5-19.

[33] Diethelm, J., 1998, Designing in an Environmental Field (Eugene, OR: Aurora Books).

[34] Carr, S., Francis, M., et al., 1992, Public Space (Cambridge: Cambridge University Press).

[35] Preziosi, D., 1979, The Semiotics of the Built Environment (Bloomington: Indiana University Press).

[36] Mumford, L., 1972, Roots of Contemporary American Architecture, 3rd edn (New York: Dover Publications).

[37] Kulski, J.E., 1971, Architecture in a Revolutionary Era (London: Aurora Publishing).

[38] Van Mechelen, I. and Michalski, R.S. (Eds), 1993, Categories and concepts, in: Cognitive Science Series (London: Academic Press).

[39] Hawkes, D., 1996, The Environmental Tradition (London: E \& FN Spon).

[40] Yeang, K., 1995, Designing with Nature (New York: McGraw-Hill). 